\title{
Rugby injury surveillance and prevention programmes: are they effective?
}

Despite the high rates of injury in rugby, the UK government plans to focus on increasing participation in the sport in schools. Andreas Freitag, Graham Kirkwood, and Allyson Pollock discuss whether surveillance and prevention programmes from around the world have reduced rugby injuries

Andreas Freitag research assistant, Graham Kirkwood research fellow, Allyson M Pollock professor

Centre for Primary Care and Public Health, Queen Mary University of London, London E1 4NS, UK

Since rugby union became a professional sport in 1995 its popularity has increased such that the Six Nations Championship in 2014 had a higher average attendance per game than either the UEFA Euro Cup 2012 or the FIFA World Cup 2014. ${ }^{123}$ Rugby (both union and league) is the third most popular team contact sport worldwide. ${ }^{4}$ Rugby union is played in around 120 countries and rugby league in around $40 .{ }^{56}$ England has the largest number of rugby union players in the world-over two million, which is almost $40 \%$ of the world total. ${ }^{5}$

The high rates of injury in rugby union and rugby league for professional and amateur players, including children, are well established and a cause for medical concern. ${ }^{7-13}$ Around $12 \%$ of child and adolescent rugby players sustain an injury severe enough to require at least seven days' absence from playing in a season. ${ }^{12} \mathrm{~A}$ meta-analysis of rugby injuries among adult rugby union players found an overall incidence of injury of 81 per 1000 player hours,${ }^{14}$ three times that of child and adolescent players (26.7 per 1000 player hours). ${ }^{12}$ So adult players can expect to be injured once every 9.3 matches on average, assuming that each match is 80 minutes long.

Recent high profile cases have exposed the mismanagement of concussion on the rugby field, sometimes with fatal consequences. ${ }^{15} 16$ The risk of concussion and reduced cognitive and motor function in later life is also high in other collision sports including American football and ice hockey. ${ }^{17}{ }^{18}{ }^{19}$ In the United States a settlement of at least \$1bn (£680m; €940m) has been granted preliminary approval by the judge in a case against the National Football League brought by former players over failure to inform them of the risks of concussion. ${ }^{20}$ Multiple autopsy findings reveal chronic traumatic encephalopathy in the brains of former professional wrestlers and players of American football, ice hockey, and rugby. ${ }^{19} 2122$

The aim of this paper is to establish whether rule changes and injury prevention strategies around the world have been successful in reducing injury rates in rugby.

\section{Collecting data}

Establishing rates of rugby injury in populations at risk requires good quality data. However, comprehensive injury surveillance systems that capture injuries occurring on the field and in training - across professional and amateur, adult and child, rugby union or rugby league - are lacking in every country except New Zealand. A comprehensive player database in New Zealand provides denominator data on injuries, as players per year by age and sex, which is essential for evaluating the effects of rule changes and prevention strategies (Ken Quarrie, personal communication, 2015).

The Rugby Football Union, the governing body for rugby union in England, only requires injuries that result in admission to hospital or death to be reported..$^{23}$ But it also funds the Community Rugby Injury Surveillance Project, which collects data on type and severity of rugby union match injuries from a sample of clubs. The number of participating clubs grew from 12 in 2008-09 to 109 of about 900 clubs in 2010-11. ${ }^{1124}$ Although serious injuries, defined as any that require hospital treatment, ${ }^{25}$ should be reported to the Scottish, English, and Irish Rugby Football Unions, their websites do not have a visible section on injury reporting and statistical monitoring. The Welsh Rugby Union does not provide any information about their policy on injury surveillance and reporting on their website. No countries other than New Zealand have compared the reliability, completeness, or accuracy of injury reports held by rugby unions with rugby injuries reported in hospitals, community health services, and schools.

New Zealand has a comprehensive national dataset of rugby injuries, which have been collected since April 1974 by the Accident Compensation Corporation (ACC). This organisation provides financial compensation and support to everyone who suffers an injury irrespective of proof of blame or citizenship. ${ }^{26}$ 
The ACC's three pillars are data collection, injury prevention, and injury compensation. Claims are either made by the claimant themselves or are automatically submitted in the case of a hospital admission. ${ }^{26}{ }^{27}$ An evaluation report published in 2008 that focused mainly on the effectiveness of injury compensation found that the ACC performed well compared with other systems because of its broad coverage, low costs, and holistic approach to case management. ${ }^{28}$ Crucially, the ACC also provides ongoing assistance and compensation for seriously injured players including income support and funds for alterations to houses and vehicles. The ACC data system runs separately from data collection by the New Zealand Rugby Union. Team managers or referees should report any injury to the head or neck, any that require hospital admission, and any that stop a player from playing for eight weeks or more through a standardised injury report form provided by the New Zealand Rugby Union on their website. ${ }^{29}$

\section{Mechanism of injury}

Systematic reviews have found that most rugby injuries occur during the tackle but that scrums are the most dangerous phase of play. This is because they have a high rate of injury relative to their short duration and a tendency to produce more severe injuries, especially in rugby union. An analysis of ACC data showed that between 1976 and $200048 \%$ (33 of 69) of permanently disabling spinal injuries occurred during the scrum, whereas $36 \%$ ( 25 of 69 ) occurred during the tackle. ${ }^{30}$ By 2001-05, after preventive measures had been taken, scrums accounted for $12.5 \%$ ( 1 of 8 ) of such injuries and tackles for $87.5 \%$ ( 7 of 8), and the number of permanently disabling spinal injuries had fallen to eight-nearly half of the number predicted (18.9) based on the previous period, presumably due to rule changes. ${ }^{30}$ Being tackled generally accounts for more injuries than active tackling. ${ }^{12}$

\section{Preventive measures}

Effective prevention strategies, such as rule changes, must be informed by data - that is, aimed at the tackle and the scrum. The reduction of permanently disabling spinal injuries in New Zealand is mainly due to a $97 \%$ fall in scrum related injuries. ${ }^{30}$ Scrum injury rates have declined considerably in rugby league in Australia since non-contested scrums were introduced in $1996 .{ }^{31}$ In 2009 World Rugby, the global governing body for rugby union, approved a number of rule changes concerning the scrum and the lineout (a way of restarting the game) after years of evaluation, and in 2010 it adjusted the rule concerning dangerous forms of the tackle (table $\Downarrow$ ). Further rule changes were approved in 2012 and 2013. ${ }^{32}$

Differences in physical size and maturity at the same age are a feature of children's development and may be associated with injury. ${ }^{34}$ Thus, matching child rugby players by size rather than age, as is done in some parts of New Zealand, may help reduce the frequency of the most severe injuries. ${ }^{35}$ Current rules of play for boys and girls are set out in the data supplement on thebmj.com. In "rugby sevens" the smaller number of players (seven rather than 15) is thought to lead players to look for gaps rather than contacts, although there is evidence of a higher incidence of concussion and of severity of concussion in professional rugby sevens than rugby $15 \mathrm{~s} .{ }^{36}$

The New Zealand Accident Compensation Act 2001 places a legal duty on the ACC "to promote measures to reduce the incidence and severity of personal injury." ${ }^{37}$ All measures have to be coordinated with governmental departments to create an efficient and effective injury prevention system. ACC data have successfully been used to inform injury prevention through the SportSmart programme. This 10 point injury prevention programme has been the template for similar initiatives focused on specific sports, including rugby, netball, football, and snow sports.

For example, in 2001 the New Zealand Rugby Union with the ACC introduced RugbySmart, which aims to educate coaches about player condition, safe techniques in contact phases of the game, and injury management. ${ }^{38}$ The Australian Rugby Union operates SmartRugby, an occupational health and safety programme, which is similar to the educational component of RugbySmart. ${ }^{39}$ Both programmes are mandatory for all coaches and referees. In 2008 the South African Rugby Union introduced BokSmart. ${ }^{40}$ Also modelled on RugbySmart, it aims to achieve behavioural changes to reduce catastrophic injuries. These three programmes focus on good injury management and primary prevention. Warm-up, safe playing techniques, and the rules of fair play are a large part of the programme. ${ }^{38} 4142$

In Scotland the “Are You Ready to Play Rugby?" programme was launched in 2009. It covers all ages and is tailored to specific age groups; youth programmes aimed at 11 to 16 year olds focus on the tackle, ruck (a loose scrum), core stability, and speed and agility, whereas programmes aimed at over $16 \mathrm{~s}$ focus more on anti-doping measures. ${ }^{43}$

In England the FMC:RUGBY project, a collaboration between the Rugby Football Union and the University of Bath, is an upcoming injury surveillance and prevention system. ${ }^{44}$ The project aims to collect injury data from participating schools for under $15 \mathrm{~s}$, under $16 \mathrm{~s}$, and under $18 \mathrm{~s}$ and to develop new warm-up and training programmes.

\section{Effectiveness of injury prevention strategies}

The Van Mechelen injury prevention model has four steps: establish the extent of the problem, establish the aetiology and mechanism of the sports injury, introduce preventive measures, and evaluate the effectiveness of prevention strategies by repeating step one. ${ }^{45}$ Only RugbySmart and BokSmart have completed all four steps. Effectiveness has been evaluated by three studies; two for RugbySmart ${ }^{27}{ }^{30}$ and one for BokSmart. ${ }^{46}$ Both programmes claim to have been successful in reducing the number of injuries and introducing behavioural changes among players. Improvements are especially seen in changes in behaviour that target catastrophic injuries. ${ }^{27} 3046$

The importance of such programmes is highlighted by the fact that rates fell only for targeted injuries. Following the implementation of RugbySmart, the rate of moderate to serious injury claims for targeted areas of the body (including neck, spine, shoulder, and knee) fell from 1689 to 1449 per million players from 2001 to 2005 . Over the same time period the rate of claims for non-targeted areas (including hand, arm, and head) increased slightly from 770 to 773 moderate to serious injury claims per million. ${ }^{27}$

Although there have been no evaluations of RugbySmart published since 2009, a report on New Zealand national news in 2014 said that moderate to serious injuries had dropped by $15 \%$ since the introduction of the programme in $2001{ }^{47}$ However, the report also showed that the number of concussion claims for rugby union increased by about $22 \%$ from 594 in 2010 to 723 in 2013. Entitlement claims, where the ACC has to pay for more than just medical treatment (for example, injury related loss of earnings, home help, or vocational rehabilitation), rose from 22 to 47 in the same period (ACC, personal 
communication, 2015). The ACC partially attributes the rise of claims to increased awareness. ${ }^{47}$ Comparisons with other countries are difficult owing to differences in study populations and injury measurement.

It is also important to understand the effectiveness of individual approaches and to tackle any challenges that could endanger the success of such programmes. ${ }^{48}$ The success of RugbySmart was largely down to an explicit recognition that a substantial proportion of injuries occurred during the tackle and that cooperation with rule changes required the involvement of experts, whose opinions were respected by players, coaches, and spectators. ${ }^{49}$

\section{UK government plans}

The UK government has selected rugby union and rugby league among the five sports it will focus on to increase the prominence of competitive sport in schools in England. Announcing the coalition government's new youth sports strategy, Jeremy Hunt promised to "work with sports such as football, cricket, rugby union, rugby league, and tennis to establish at least 6000 partnerships between schools and local sports clubs by 2017." The government hopes to put 1300 links in place between schools and rugby union organisations, and 1000 links with rugby league..$^{50}$ But most rugby injury surveillance and prevention programmes established since the late 2000s have not been evaluated. The safety of the game, effectiveness of prevention programmes, and recent changes to the laws of the game are unknown.

Given that children are more susceptible to injuries such as concussion and often take longer to recover fully, ${ }^{51}$ the government's plan to increase funding of and participation in rugby in schools in the absence of a comprehensive system for injury surveillance and prevention (including tertiary prevention and rehabilitation) is worrying. Only by collecting injury data and by providing feedback to individuals and organisations working on safety initiatives will the short and long term effects of injury prevention programmes, whether for rugby or any other sport, be known.

Many countries, including the UK, have inadequate child injury surveillance systems. Under the United Nations Convention on the Rights of the Child governments have a duty to protect children from risks of injury. As a signatory to the convention, the UK government should ensure the safety and effectiveness of sports and that injury surveillance and prevention strategies are established before proceeding with its plans to target funding and increase participation in a high risk collision sport such as rugby.

Acknowledgments: We thank Barts Charity for funding staff (GK and AF) through the Centre for Trauma Sciences. We thank Ken Quarrie for reviewing and commenting on the manuscript and for the material on tertiary prevention.

Contributors and sources: AMP conceived, directed, and reviewed the article throughout. AF and GK researched and drafted the manuscript with contributions from AMP; AF, GK, and AMP edited and approved the final versions for publication. AMP is the guarantor.

Competing interests: We have read and understood BMJ policy on declaration of interests and have no relevant interests to declare.

Provenance and peer review: Not commissioned; externally peer reviewed.

Six Nations Rugby. RBS Six Nations 2014. www.rbs6nations.com/

UEFA Euro 2012. www.uefa.com/uefaeuro/finals/history/memories/newsid=1837498.html.

FIFA World Cup 2014. $w w w$.fifa.com/worldcup/news $/ y=2014 / m=9 /$ news=2014-fifa-worldcup-braziltm-in-numbers-2443025.html.
4 Kaplan KM, Goodwillie A, Strauss EJ, Rosen JE. Rugby injuries: a review of concepts and current literature. Bull NYU Hosp Jt Dis 2008:66:86-93.

5 IRB. International Rugby Board 2013. https://rugbyredefined.files.wordpress.com/2014/ 05/irb-dev-glob-map.pdf.

6 Rugby League International Federation. Rankings 2015. www.rlif.com/rankings.

7 Carter M. The unknown risks of youth rugby. BMJ 2015;350:h26.

8 Gardner AJ, Iverson GL, Williams WH, Baker S, Stanwell P. A systematic review and meta-analysis of concussion in rugby union. Sports Med 2014:44:1717-31.

9 Gardner A, Iverson GL, Levi CR, et al. A systematic review of concussion in rugby league. Br J Sports Med 10 Apr 2014, doi:10.1136/bjsports-2013-093102.

10 Rugby Football Union. England professional rugby injury surveillance project 2012-13 Season Report. 2014. www.englandrugby.com/mm/Document/MyRugby/Players/01/30/ 36/13/Injury_audit_report_Neutral.pdf.

11 Rugby Football Union. Community rugby injury surveillance project (CRISP). www.bath ac.uk/health/projects/rfu-rugby-injury/.

12 Freitag A, Kirkwood G, Scharer S, Ofori-Asenso R, Pollock AM. Systematic review of rugby injuries in children and adolescents under 21 years. Br J Sports Med 2015;49:511-9.

13 Kirkwood G, Parekh N, Ofori-Asenso R, Pollock AM. Concussion in youth rugby union and rugby league: a systematic review. Br J Sports Med 2015;49:506-10.

14 Williams S, Trewartha G, Kemp S, Stokes K. A meta-analysis of injuries in senior men's professional rugby union. Sports Med 2013;43:1043-55.

15 Bull A. Death of a schoolboy: why concussion is rugby union's dirty secret. Guardian 2013 Dec 13. www.theguardian.com/sport/2013/dec/13/death-of-a-schoolboy-ben-robinsonconcussion-rugby-union.

16 Jenkins G. Smith 'snake dance' prompts change to concussion trial. ESPN 2013 Sep 5. www.espn.co.uk/scrum/rugby/story/196939.html.

17 Tremblay S, De Beaumont L, Henry LC, et al. Sports concussions and aging: a neuroimaging investigation. Cereb Cortex 2013;23:1159-66.

18 De Beaumont $\mathrm{L}$, Theoret $\mathrm{H}$, Mongeon $\mathrm{D}$, et al. Brain function decline in healthy retired athletes who sustained their last sports concussion in early adulthood. Brain 2009;132:695-708.

19 McKee AC, Cantu RC, Nowinski CJ, et al. Chronic traumatic encephalopathy in athletes: progressive tauopathy after repetitive head injury. J Neuropathol Exp Neurol 2009;68:709-35.

20 NFL concussion settlement worth $\$ 1$ bn is 'close.' BBC 2015 Feb 9. www.bbc.co.uk/news/ world-us-canada-31269252.

21 McKee AC, Stern RA, Nowinski CJ, et al. The spectrum of disease in chronic traumatic encephalopathy. Brain 2013;136:43-64.

22 Gardner A, Iverson GL, McCrory P. Chronic traumatic encephalopathy in sport: a systematic review. Br J Sports Med 2014;48:84-90.

23 England Rugby. Injury reporting. Jul 2014. www.englandrugby.com/news/injury-reporting $1289995 /$.

24 England Rugby. 2015. www.englandrugby.com/fixtures-and-results/competitions/.

25 Irish Rugby Football Union. Serious injury report form. www.irishrugby.ie/downloads/ IRFU Serious Injury Report Form.pdf.

26 Accident Compensation Corporation. www.acc.co.nz/.

27 Gianotti SM, Quarrie KL, Hume PA. Evaluation of RugbySmart: a rugby union community injury prevention programme. J Sci Med Sport 2009;12:371-5.

28 PriceWaterhouseCoopers. Accident Compensation Corporation New Zealand. Scheme review. March 2008. www.acc.co.nz/PRD_EXT_CSMP/groups/external_communications/ documents/reports results/prd ctrb076534.pdf.

29 New Zealand Rugby Union. Injury reporting. www.coachingtoolbox.co.nz/rugbysmart/ injury-reporting/.

30 Quarrie KL, Gianotti SM, Hopkins WG, Hume PA. Effect of nationwide injury prevention programme on serious spinal injuries in New Zealand rugby union: ecological study. BMJ 2007;334:1150.

31 Carmody DJ, Taylor TK, Parker DA, Coolican MR, Cumming RG. Spinal cord injuries in Australian footballers 1997-2002. Med J Aust 2005;182:561-4.

32 Rugby Football History. History of the laws of rugby football. www.rugbyfootballhistory. com/laws.htm.

33 England Rugby. Governance. Regulations. 2013. www.englandrugby.com/governance/ regulations/.

34 O'Rourke KP, Quinn F, Mun S, et al. A comparison of paediatric soccer, gaelic football and rugby injuries presenting to an emergency department in Ireland. Injury 2007;38:104-11.

35 McCoy GF, Piggot J, Macafee AL, Adair IV. Injuries of the cervical spine in schoolboy rugby football. J Bone Joint Surg Br 1984;66:500-3.

36 Fuller CW, Taylor A, Raftery M. Epidemiology of concussion in men's elite Rugby-7s (Sevens World Series) and Rugby-15s (Rugby World Cup, Junior World Championship and Rugby Trophy, Pacific Nations Cup and English Premiership). Br J Sports Med 2015;49:478-83.

37 New Zealand Legislation. Accident Compensation Act 2001. Section 263(1). www. legislation.govt.nz/act/public/2001/0049/latest/DLM103143.html.

38 Coaching Toolbox. RugbySmart. www.coachingtoolbox.co.nz/rugbysmart/introduction/

39 Australian Rugby. Smart Rugby. www.rugby.com.au/coaching/SmartRugby/ ProgramFeatures.aspx.

40 BokSmart. http://boksmart.sarugby.co.za/.

41 Apple iTunes Store. Rugby Smart app. https://itunes.apple.com/nz/app/rugby-smart/ id635147550?mt=8.

42 BokSmart. Medical Protocols. http://boksmart.sarugby.co.za/content/medical-protocol.

43 Scottish Rugby. RugbyReady practical course. www.scottishrugby.org/get-involved/playgame/are-you-ready-play/rugbyready-practical-courses.

44 University of Bath. FMC rugby project. https://plus.google.com/104010750079272460420/ posts.

45 van Mechelen W, Hlobil H, Kemper HC. Incidence, severity, aetiology and prevention of sports injuries. A review of concepts. Sports Med 1992;14:82-99.

46 Brown JC, Gardner-Lubbe S, Lambert MI, Van Mechelen W, Verhagen E. The BokSmart intervention programme is associated with improvements in injury prevention behaviours of rugby union players: an ecological cross-sectional study. Inj Prev 21 Nov 2014, doi:10. 1136/injuryprev-2014-04132.

47 Teen rugby ACC concussion claims on the rise. TVNZ2014 Jul 8. http://tvnz.co.nz/nationalnews/teen-rugby-acc-concussion-claims-rise-6022356.

48 Dowswell T, Towner EM, Simpson G, Jarvis SN. Preventing childhood unintentional injuries_-what works? A literature review. Inj Prev 1996:2:140-9. 


\section{Key messages}

Formal public injury surveillance and prevention systems have been successfully established for rugby in New Zealand Injury prevention programmes must be evaluated to ensure a successful approach to reducing injury rates

Most rugby injury surveillance and prevention programmes have not completed all steps of Van Mechelen's injury prevention model, so the effect of injury prevention initiatives on reducing injuries and optimising the outcomes of injury is not known

The effectiveness of recent rule changes has yet to be evaluated

The UK government plan to fund and to increase participation in rugby in schools has not been informed by injury data and is happening in the absence of systems for injury surveillance and prevention

49 Chalmers DJ, Simpson JC, Depree R. Tackling rugby injury: lessons learned from the implementation of a five-year sports injury prevention program. J Sci Med Sport 2004;7:74-84.

50 Department for Culture Media and Sport. Creating a sporting habit for life. A new youth sport strategy. 2012. www.sportengland.org/media/130949/DCMS-Creating-a-sportinghabit-for-life-1-.pdf.

51 Halstead ME, Walter KD. American Academy of Pediatrics. Clinical report-sport-related concussion in children and adolescents. Pediatrics 2010;126:597-615.

\section{Accepted: 13 March 2015}

Cite this as: BMJ 2015;350:h1587

(๑) BMJ Publishing Group Ltd 2015 


\section{Table}

\section{Table 1/ Selected changes to the rules of rugby union for the tackle and the scrum}

\begin{tabular}{|c|c|c|}
\hline Year & Tackle & Scrum \\
\hline \multicolumn{3}{|c|}{ World Rugby $^{32}$} \\
\hline 2005 & & $\begin{array}{l}3.13(a) \text { : If after a front row player has been sent off or during the time a front } \\
\text { row player is temporarily suspended there are no further front row players } \\
\text { available from the nominated team, then uncontested scrums will be ordered }\end{array}$ \\
\hline \multirow[t]{2}{*}{2009} & 10.4(e): Tackling above shoulders considered dangerous play & \multirow{2}{*}{$\begin{array}{l}\text { 20.3(f): All players in a scrum, other than front-row players, must bind on a } \\
\text { lock's body with at least one arm prior to the scrum engagement }\end{array}$} \\
\hline & $\begin{array}{l}\text { 10.4(i): Lifting a player off the ground and driving the player into the ground } \\
\text { while the feet are still off the ground such that the player's head and/or } \\
\text { upper body come into contact with the ground first is considered dangerous } \\
\text { play }\end{array}$ & \\
\hline 2010 & 10.4(h): A player must not charge into ruck or maul & Changes to scrum formation for under 19 s rugby in part $20.1(\mathrm{f})$ \\
\hline 2011 & $\begin{array}{l}\text { 10.4(j): Lifting a player off the ground and driving the player into the ground } \\
\text { while the feet are still off the ground such that the player's head and/or } \\
\text { upper body come into contact with the ground at all is considered } \\
\text { dangerous play }\end{array}$ & \\
\hline \multicolumn{3}{|c|}{ Rugby Football Union ${ }^{33}$} \\
\hline 2014 & & $\begin{array}{l}\text { No player to take part in scrums until he has reached his 18th birthday; } \\
\text { uncontested scrums to be used when a front row player is required to be } \\
\text { replaced and there is no suitable front row replacement available, or when the } \\
\text { referee deems it unsafe to start or continue a match with contested scrums }\end{array}$ \\
\hline
\end{tabular}

